\title{
Linaje, poder y cultura de la nobleza de Guadalcázar. Aproximación al eclesiástico Luis Fernández de Córdoba y Portocarrero
}

\author{
Sarai HERRERA PéREZ \\ Universidad de Jaén \\ Departamento de Patrimonio Histórico \\ shperez@ujaen.es
}

\section{RESUMEN}

La presente comunicación pretende analizar la interesante personalidad de Luis Fernández de Córdoba y Portocarrero a través de las empresas culturales que desarrolla. En este patronazgo, no sólo advertimos connotaciones espirituales, sino también un componente de prestigio social.

Palabras clave: Luis Fernández de Córdoba; Guadalcázar; eclesiástico; patronazgo cultural; linaje.

\section{Lineage, power and culture of the Guadalcázar nobility. Approximation to the ecclesiastic Luis Fernández of Córdoba y Portocarrero}

\begin{abstract}
The present communication analyzes the interesting personality of Luis Fernández de Córdoba y Portocarrero through the cultural patronage he developed. In this patronage, we don't only find spiritual connotations, but also a component of familiar prestige and social distinction.
\end{abstract}

Key words: Luis Fernández de Córdoba; Guadalcázar; ecclesiastic; cultural patronage; social distinction. 
Nuestro personaje, Luis Fernández de Córdoba y Portocarrero, nació en la capital cordobesa en febrero del año 1555. Fue hijo del VIII señor de Guadalcázar, don Antonio Fernández de Córdoba, y de Brianda Portocarrero de Mendoza, dama natural de Écija y nieta del primer conde de Palma del Río. Asimismo, fue sobrino del obispo de Badajoz, Andrés Fernández de Córdoba y Carvajal, y tío de don Diego Fernández de Córdoba, primer marqués de Guadalcázar que llegaría a ejercer como virrey de Nueva España y del Perú. Por tanto, desde un primer momento, podemos advertir que nos encontramos ante una personalidad que se adscribe a un ámbito familiar de poder y prestigio ${ }^{1}$.

A los once años de edad comenzó sus estudios en la Universidad de Salamanca, en la que obtuvo el doctorado en Derecho Civil y Canónico. Posteriormente se trasladó a Roma, hasta el momento en el que el pontífice Gregorio XIII le nombró deán de la Catedral cordobesa ${ }^{2}$. Durante el periodo que comprende su deanato, fue benefactor de la Orden de los Carmelitas Descalzos ${ }^{3}$, hecho que aparece documentado en las fuentes ${ }^{4}$.

Poco después, el monarca Felipe III lo designó obispo de la diócesis salmantina. La noticia, según Gómez Bravo, fue acogida con gran entusiasmo por la ciudad de Córdoba ${ }^{5}$. El desempeño de este episcopado se caracterizaró por la especial atención que prestó a los conventos y por la práctica de la piedad cristiana hacia los más necesitados $^{6}$. Asimismo, cabe destacar que en el año 1604 celebró un sínodo diocesano cuyas actas serían publicadas en 1606 .

El día 9 de febrero de 1613 recibiría la designación de presidir la sede malagueña ${ }^{7}$, para poco después, en diciembre del año 1614, ser promovido a la misma. Ya a finales del año 1615 debía encontrarse en Málaga puesto que presidió el cabildo celebrado el 2 de diciembre, donde expresó tanto su deseo de visitar la Iglesia Catedral con el objeto de conocer aquellos elementos que precisaban reforma, como de socorrer a los niños expósitos ${ }^{8}$. En este sentido, su labor caritativa también se dirigiría hacia los pobres de la cárcel, cuyas condiciones de habitabilidad mejoró, llegando incluso a liberarles cuando fuera posible. A la vez, financió una casa de acogida de mujeres para procurarles el sustento necesario. Por otra parte, a lo largo del ejercicio de su

1 Para obtener una visión aproximativa a este miembro del linaje de la Casa de Guadalcázar vid.: AGUAYO EGIDO, Francisco, "El arzobispo Luis Fernández de Córdoba”, en CRIADO COSTA, Joaquín (ed.), Actas del XV Congreso Nacional de Cronistas Españoles y XXV Reunión Anual de Cronistas Cordobeses (Córdoba, 1994), Córdoba, Diputación de Córdoba, 1997, pp. 137-149.

2 Sucede a don Alonso Fernández de Córdoba, siendo el cuarto miembro del linaje que ocupa este cargo.

3 MORALES Y PADILLA, Andrés, Historia general de la Muy Leal Ciudad de Cordova y de sus Nobilísimas Familias, Córdoba, Ayuntamiento de Córdoba, 2006 (1662), vol. II, p. 288.

4 SANTA TERESA, Silverio de, Historia del Carmen Descalzo en España, Portugal y América, vol. IV, Burgos, Tipografía El Monte Carmelo, 1935 (1878), p. 312.

5 GÓMEZ BRAVO, Juan, Catálogo de los obispos de Córdoba y breve noticia histórica de su Iglesia Catedral y obispado, Córdoba, Imprenta de don Juan Rodríguez, 1778, p. 569.

6 GÓNZALEZ DÁVILA, Gil, Teatro eclesiástico de las Iglesias Metropolitanas y Catedrales de los Reynos de las dos Castillas, vidas de sus Arzobispos, y Obispos, y cosas memorables de sus sedes, Madrid, Imprenta de Pedro de Horna y Villanueva, 1647, pp. 357-358.

7 Para obtener una visión general de la diócesis malacitana vid: MONDÉJAR CUMPIAN, Francisco, Obispos de la Iglesia de Málaga, Córdoba, Obra Social y Cultural de Cajasur, 1998.

8 ACCM. AC, legajo n. ${ }^{\circ} 19,1615$, f. 20 v. ${ }^{\circ}$. 
cargo se preocupó de conocer y visitar personalmente cada una de las instituciones que conformaban su obispado.

Pero su trayectoria eclesiástica no se detiene aquí, sino que, con fecha de 4 de julio de 1622, es promovido a la silla arzobispal de Santiago de Compostela ${ }^{9}$. De todos modos, sin haber tenido apenas ocasión de desarrollar su labor como arzobispo de la villa compostelana debido a sus múltiples ocupaciones en la Corte $^{10}$, el 12 de marzo de 1624 se efectúa en Roma su nombramiento como titular del arzobispado de Sevilla. La toma de posesión fue realizada el 23 de mayo por Francisco de Monsalve, deán de la iglesia patriarcal, que sucedió en el cargo a otro ilustre varón de la Casa de los Córdobas, Diego Fernández de Córdoba y Lasso de Castilla. La entrada en Sevilla de don Luis Fernández de Córdoba se produjo el día 5 de julio, siendo recibido con júbilo por los dos cabildos de la ciudad en el exterior de su recinto amurallado ${ }^{11}$.

Sin embargo, cuando la diócesis hispalense seguía congratulándose con su presencia, al nuevo arzobispo le sorprende la muerte un 26 de junio de 1625, poco después de haber otorgado testamento ante Diego Martínez, escribano público de la ciudad de Sevilla. Su cuerpo sería depositado provisionalmente en la capilla de Nuestra Señora de la Antigua de la catedral ${ }^{12}$. La noticia de la defunción se puso en conocimiento del cabildo malacitano, que acuerda dedicarle unas honras suntuosas, que serían realizadas el día 12 de julio del año 1625.

Si nos centramos en el análisis de su testamento, podemos advertir cómo dicho documento se inicia encomendando su alma a Dios y pidiendo ser enterrado en Guadalcázar, núcleo del poder de su familia, a los pies de la Virgen de la Caridad:

"Por la mucha devoción que sienpre e tenido a la imagen de nuestra señora de la Caridad de la Villa de Guadalcáçar, donde e edificado vn convento de frayles carmelitas descalços, quiero y es mi voluntad que mi cuerpo sea sepultado en la yglesia..."13.

Por otra parte, en recuerdo a su sobrino, virrey en Nuevo Mundo, que le había encomendado a un hijo, declara:

\footnotetext{
9 BARREIRO MALLÓN, Baudilio, "Iglesias de Santiago de Compostela y Tuy-Vigo”, en MARTÍ I BONET, Josep María (coord.), Historia de las diócesis españolas, vol. XIV, Madrid, Biblioteca de Autores Cristianos, 2002, p. 223. Llegados a este punto, debemos tomar en consideración que los arzobispos compostelanos del siglo XVII responden al conocido tipo de prestigio familiar, en consonancia con la recuperación nobiliaria de finales del siglo XVI, que también contará con una manifestación en el ámbito de la Iglesia. De hecho, los primeros arzobispos compostelanos de esta centuria corresponden al prototipo de "arzobispo-noble" que se hará tan característico a partir de este momento.

10 Esta circunstancia ocasiona que, en esta etapa, no encontremos empresa alguna que se desarrolle bajo su patronazgo.

11 ORTÍZ DE ZÚÑIGA, Diego, Anales eclesiásticos y secvlares de la muy noble y muy leal ciudad de Sevilla, vol. II, Madrid, Imprenta Real, 1795 (1646), p. 310.

12 FERNÁNDEZ DE BETHENCOURT, Francisco, Historia Genealógica y Heráldica de la Monarquía española, Casa Real y Grandes de España, vol. IX, Madrid, Imprenta de E. Teodoro, 1905, p. 437.

13 AGAS, legajo 486, fols. 22-28. El convento será finalmente suprimido, por lo que sus restos mortales y los de su sobrino el virrey Diego Fernández de Córdoba, son trasladados, el día 31 de julio de 1845, al templo parroquial de la villa.
} 
“...Don Diego Fernández de Córdova marqués de Guadalcáçar, mi sobrino, virrey que a sido de la nueva España y al pressente lo es del Pirú, para yr para aquellas partes dexó en mi poder a don Françisco Fernández de Córdova, su hijo, de hedad de siete messes, para que yo le criase e dispusiese dél, lo qual e hecho con el amor y voluntad que devo desde aquella hedad hasta la que tiene al pressente de catorçe años"14.

A continuación, pasa a mencionar las abundantes dotaciones que había concedido al convento del Císter que fundó en la villa de Guadalcázar. Asimismo, nombra como heredero universal al convento de Nuestra Señora de la Caridad de Guadalcázar y como albaceas, a los señores condes de Palma, a su sobrino el virrey Diego Fernández de Córdoba, al deán y chantre de la Iglesia sevillana, a su primo Rodrigo de Narváez, al penitenciario Gonzalo de Córdoba, al visitador Juan de Zapata, al doctor Eugenio de Chiriboga y finalmente, al licenciado Fernando de Ojeda, oidor de la Real Audiencia.

Sin lugar a dudas, el análisis de este testamento arroja datos de gran interés que no sólo hacen referencia a los bienes que lega, sino también a sus relaciones en el contexto de la familia. En efecto, podemos advertir una relación cercana con su sobrino, don Diego Fernández de Córdoba, primer marqués de Guadalcázar que llegaría a desempeñar los cargos de virrey de Nueva España y del Perú. De cualquier modo, en el trasfondo de este trato familiar, también subyacen otro tipo de connotaciones que alcanzan al ámbito del poder. Y es que, probablemente, la influencia del eclesiástico Luis Fernández de Córdoba tuvo repercusión en el hecho de que su sobrino Diego encabezara por vez primera el marquesado de Guadalcázar, que hasta entonces había sido señorío.

En este sentido, no podemos obviar la relevancia que ejerció el eclesiástico en el panorama político de su época, tal y como se advierte a través del encargo que recibe de parte de Felipe II de realizar la visita al Capítulo Provincial de religiosos de San Francisco de Padua en Andalucía y de proceder a la reforma de la orden de San Basilio en territorio andaluz y castellano. Pero si hay alguna prueba manifiesta de su vinculación con la monarquía española y la correspondencia entre ésta y nuevo estatus de la Casa de Guadalcázar, la encontramos en la alta estima que le otorgó Felipe III quien, en atención a sus cualidades y virtudes, lo designa para dirigir la sede episcopal salmantina ${ }^{15}$. Este nombramiento tendrá lugar en la congregación celebrada en Valladolid en el año 1602, a la que don Luis Fernández de Córdoba acude como deán de la catedral cordobesa ${ }^{16}$.

De cualquier modo, su influencia no se detendrá aquí, sino que también se prolongará a lo largo de los años que comprende el reinado de Felipe IV, quien lo promoverá para ocupar la silla arzobispal de Santiago de Compostela, prueba manifiesta de su ascendente carrera eclesiástica. Asimismo, solicitará su consejo con relación a las intenciones del príncipe Carlos de Inglaterra de acceder a la mano de la infanta doña María. En aquel mismo momento, el nuevo arzobispo, como capellán mayor del Rei-

$14{ }^{1}$ AGAS: Legajo 486, fol.26.

15 Recordemos que al monarca corresponde la constitución del marquesado de Guadalcázar en el año 1609.

16 GÓMEZ BRAVO, Juan (1778), op. cit., p. 570. 
no, presidirá la procesión madrileña del Corpus Christi, que contó con la asistencia del nuncio apostólico y de los cardenales Spínola y Zapata.

En definitiva, todos y cada uno de estos gestos nos resultan muestras inequívocas para constatar la hipótesis que planteábamos, y apuntar hacia una clara concordancia entre el contexto de poder en el que supo situarse el eclesiástico y la pujanza de la rama del linaje a la que pertenece.

Pero si cada uno de los aspectos en los que hemos fijado nuestra atención se ha mostrado proclive a la definición de don Luis Fernández de Córdoba y Portocarrero como un personaje de relevancia en el contexto al que pertenece, tampoco debemos obviar su trascendencia desde una perspectiva cultural, es decir, la contribución que realiza a través de las empresas que se desarrollan bajo su patrocinio. En este ámbito, don Luis Fernández de Córdoba ejerce un patronazgo de cierta proyección, tal y como puede advertirse mediante las muestras que se ponen de manifiesto en: las fundaciones eclesiásticas, la dotación de iglesias y capillas, o los bienes artísticos que sufragó. Desarrolla, de este modo, una tarea gracias a la cual no sólo se materializa el desempeño de su labor como eclesiástico, sino que incluso se contribuye a que el grupo de poder al que pertenece, la Casa de Guadalcázar, llegue perpetuar su rastro y a configurar su solar.

Por tanto, más allá de que las empresas acometidas bajo su protección puedan llegar a ser o no representativas en cuanto a su calidad artística, debemos de atender a su pertenencia como parte integrante de un programa personal que cuenta con unas pronunciadas pretensiones de ostentación, prestigio social y rivalidad familiar. Por ello, este patronazgo no responde exclusivamente a una percepción cultural, a una valoración formal de los objetos o al gusto por ellos, sino sobre todo a ciertas apreciaciones propagandísticas. De cualquier manera, en el ámbito de las empresas acometidas por nuestro eclesiástico, tenemos que establecer una clara diferenciación entre aquellas que emprende en el ejercicio de su labor episcopal, de aquellas que ejecuta desde un punto de vista personal. Pero a pesar de esta distinción, en ambos casos subyacen una serie de factores que actúan a modo de denominador común. Así, a través del arte o de la heráldica, se expresa tanto un definido concepto de autorrepresentación como un deseo de perpetuación de la memoria, no sólo de si mismo sino también de su linaje. Este aspecto se pone de relieve, por ejemplo, en la presencia de las armas familiares en lugar de las correspondientes a su ejercicio episcopal, tal y como veremos en el retablo mayor del templo parroquial de Guadalcázar.

En el ámbito que corresponde al desempeño de su labor como eclesiástico demostrará, desde un primer momento, su deseo de configurar e inmortalizar una imagen de poder. En este contexto sus acciones fueron encaminadas hacia el realce su figura a través de las aportaciones a las respectivas diócesis que ocupó. Buena parte de sus esfuerzos se destinarían a la fundación de nuevas sedes conventuales, tal y como se aprecia en el periodo que comprende su deanato en Córdoba. En esta etapa, que comprende desde el año 1583 al 1601, don Luis participaría de la fundación del convento de San Roque, que fue llevada a cabo por el mismísimo San Juan de la Cruz. Tampoco debemos obviar la iniciativa que desarrolló para la fundación en Córdoba de un convento de carmelitas descalzas, institución que recibió la advocación de San- 
ta Ana ${ }^{17}$. Para llevar a buen puerto esta empresa, recibiría el firme apoyo del obispo cordobés Francisco Pacheco ${ }^{18}$.

En esta misma línea prosigue durante su episcopado en Salamanca, “...Diócesis a la que en el segundo año de su Prelacia dio vna crecida limosna para la fábrica de su Iglesia" 19 . Asimismo, procedería a la reedificación de los palacios episcopales ${ }^{20}$.

Pero sin lugar a dudas la sede malacitana se convertirá en la más beneficiada de cuantas preside, auspiciando la construcción y reedificación de numerosas iglesias y ermitas y favoreciendo, asimismo, la institución de nuevas órdenes religiosas en la ciudad. Entre ellas, a modo de ejemplo, debemos referir el caso de la Orden de los Capuchinos. Con ello, procedería a la ampliación del palacio episcopal ${ }^{21}$ y a la reconstrucción el seminario de la Catedral, al que también dota de nuevas ordenanzas para su gobierno.

Tampoco olvida las labores de mantenimiento de la sede catedralicia y así, emprende reformas en la capilla mayor de la Catedral, en este caso, relativas a la renovación del pavimento. A este respecto, debemos de valorar el contexto en el que se encuentra la fábrica catedralicia en estos momentos. A finales del siglo XVI, ante la falta de liquidez en las arcas capitulares, las obras quedarán suspendidas temporalmente. Ante esta situación, el monarca Felipe II opta por la intervención de Francisco de Mora para que entregue al deán las trazas realizadas por él. Fallecidos los arquitectos Vergara el Mozo y Minjares, se decide nombrar maestro mayor a Pedro Díaz de Palacios, aparejador de la Catedral desde 1599 y se procede a tomar prestadas las sumas necesarias para proseguir las obras.

Otra de las empresas que desarrolla nuestro obispo para la Catedral es el antepecho que se dispondría alrededor del altar mayor, obra que sería asignada, en el año 1621, al carpintero Lucas Pérez de Aldana. Por otro lado, el espacio que comprende el coro constituiría otra de las intervenciones que don Luis Fernández de Córdoba plasmara en el recinto catedralicio malacitano. El comienzo de la nueva centuria supondría la continuación de sus obras, siendo estrenado el día 5 de junio de 1631. El coro contaba con tres puertas cerradas en el testero, y dos puertas laterales, una abierta para el paso y respiración del coro y la otra clausurada con un tabique para poner libros ${ }^{22}$.

17 Se da la particularidad de que su tía, doña Brianda de Córdoba, hermana del que fuera séptimo señor de Guadalcázar, ingresaría en esta comunidad poco después de su fundación.

18 ORTÍ BELMONTE, Miguel Ángel, Córdoba monumental artística e histórica, vol. II, Córdoba, Diputación Provincial de Córdoba, 1980, p. 158.

19 Se refiere a la fábrica de la Catedral Nueva. De todos modos, hay que tener en cuenta que la primera mitad del siglo XVII no resulta demasiado fructífera en su proceso constructivo, ya que será a partir de la segunda mitad de la centuria cuando las obras sean retomadas con un mayor impulso. Con relación al estado en el que se encuentra el templo catedralicio de Salamanca en estos momentos vid.: PEREDA ESPESO, Felipe, "La Catedral de Salamanca en la segunda mitad del siglo XVII", en Boletín del Seminario de Estudios de Arte y Arqueología, n. ${ }^{\circ} 60,1994$, pp. $393-402$.

20 No se conserva vestigio alguno de esta intervención, ya que el edificio que se erige actualmente corresponde a las reformas realizadas en el siglo XVIII.

21 La ampliación que acometerá don Luis Fernández de Córdoba permanece oculta bajo las intervenciones que se realizan posteriormente, en el siglo XVIII. Las trazas de esta centuria corresponderán al arquitecto Antonio Ramos.

22 SAURET GUERRERO, Teresa, La Catedral de Málaga, Málaga, Diputación de Málaga, 2003, p. 97. 
Pese a todo y sin lugar a dudas, la donación más relevante que el obispo legará a la Catedral de Málaga será un frontal de plata ${ }^{23}$. Esta pieza fue atribuida, en principio, al platero Juan de Ledesma ${ }^{24}$ pero en la actualidad, en sus últimas catalogaciones no se precisa su autoría, aunque como norma general se mantiene su vinculación a talleres de platería sevillanos. En concreto, se estima que la pieza, actualmente custodiada en el museo catedralicio de Málaga, fue entregada a la sede en el momento en el que don Luis Fernández de Córdoba ya desempeñaba la titularidad de la archidiócesis hispalense ${ }^{25}$. Esta reciente hipótesis sobre su factura, resultaría más que factible si se conservara el contrato de ejecución, sin embargo simplemente se cuenta con una escueta referencia en las actas capitulares de 1620, documento en el que el obispo declara su interés por donar un frontal de plata con destino al altar mayor. En la composición, junto al emblema de su episcopado se advierten, de un lado, las representaciones de los mártires malagueños San Ciriaco y Santa Paula y de otro, en el medallón central, la escena de la Encarnación, advocación bajo la que se erige el templo mayor de la ciudad.

La capital malacitana constituiría otro de los núcleos en los que el obispo pretende manifestar el ejercicio de su episcopado. La ciudad no escapa a las pretensiones de don Luis Fernández de Córdoba, que incluso llega a materializar su poder por medio del desarrollo de intervenciones urbanísticas en Málaga. En este aspecto destaca el denominado como torreón del Obispo, que mandó levantar bajo su patrocinio en el año 1621 con la finalidad de reforzar el sistema amurallado del muelle viejo y favorecer, por tanto, la seguridad de la capital malagueña. La obra sería dirigida por Pedro Díaz de Palacio ${ }^{26}$.

Si nos centramos ya en el caso de Sevilla, debemos tener en cuenta que el hecho de que don Luis Fernández de Córdoba ejerciera una tutela efímera sobre la sede hispalense no impediría el desarrollo de un testimonio material de su arzobispado, que en este caso, se manifestará por medio de las reformas que emprende en el Palacio Arzobispal ${ }^{27}$. Estas obras se centran en la realización de una nueva escalera que se localiza en el sector norte, próximo al tercero de los patios que se encuentran en este recinto $^{28}$. Consta de un único tiro y se cubre por una bóveda labrada que muestra la presencia de las armas del prelado.

23 Con relación a esta obra vid:: SÁNCHEZ-LAFUENTE GEMÁR, Rafael, "Frontal de altar”, en SÁNCHEZLAFUENTE GEMAR, Rafael (coord.), El fulgor de la Plata, catálogo de la exposición (Córdoba, 2007), Bilbao, Consejería de Cultura de la Junta de Andalucía, 2007, p. 260.

24 SÁNCHEZ-LAFUENTE GÉMAR, Rafael, "Frontal de altar", en SÁNCHEZ-LAFUENTE GÉMAR, Rafael (coord.), El esplendor de la memoria. El arte de la Iglesia de Málaga, catálogo de la exposición (Málaga, 1998), Málaga, Consejería de Cultura de la Junta de Andalucía y Obispado de Málaga, 1998, p. 166.

25 Junto al frontal de altar donó una cruz procesional que no se ha conservado.

26 Con relación a este arquitecto vid: AGUILAR GARCÍA, María Dolores, Pedro Díaz de Palacio: Maestro Mayor de la Catedral de Málaga, Málaga, Universidad de Málaga, 1987.

27 El edificio tiene su origen en el palacio destinado a la residencia del que fuera primer obispo de la diócesis sevillana, don Remondo. A lo largo de los siglos se fue ampliando hasta mediados de los 500, momento en el que se concibe el conjunto arquitectónico que se erige actualmente. De todos modos, existen intervenciones posteriores, entre ellas la portada, obra de Lorenzo Fernández de Figueroa y Diego Antonio Díaz.

28 FALCÓN MÁRQUEZ, Teodoro, El Palacio Arzobispal de Sevilla, Córdoba, Obra Social y Cultural de Cajasur, 1997, p. 122. 
Sin embargo, como ya hemos referido, las empresas que promueve don Luis Fernández de Córdoba y Portocarrero también tendrán su repercusión en el núcleo del poder de la Casa nobiliaria a la que pertenece, es decir, en Guadalcázar. En esta villa, emprenderá una serie de encargos destinados a la configuración del solar familiar y a la perpetuación de la memoria del linaje, con unas evidentes connotaciones de distinción social. Entre estas acciones se encuentra su colaboración junto a su padre, sus tíos Andrés y Lorenzo y su hermano Francisco, en la institución del convento de Carmelitas Descalzos de Guadalcázar, que se produce con fecha de 24 de marzo de 1585. Paralelamente, como nueva manifestación del poder en el núcleo territorial de su familia, don Luis reedifica la iglesia parroquial.

En esta línea, hay que destacar que, poco después de que se produjera su incorporación a la sede de Málaga, nuestro personaje demuestra de nuevo la fuerte presencia que sigue teniendo en su recuerdo la villa de Guadalcázar: en los inicios de su episcopado, don Luis Fernández de Córdoba ordena la ejecución de la que será, sin duda, la empresa artística de mayor envergadura que acometa en el epicentro de poder de su familia, a saber, el retablo mayor de la parroquia de Nuestra Señora de Gracia, que sería ejecutado en el período que comprende desde el año 1616 al $1620^{29}$.

Se desconoce el autor de las trazas, pero en este contexto debemos valorar que en estos años se empieza a trabajar en el retablo mayor de la catedral de Córdoba y que el influjo de los diseños realizados por Alonso Matías se dejaría sentir en la retablística contemporánea de la provincia de Córdoba. Atendiendo a sus características, podríamos emplazar a este retablo en esta misma órbita de los esquemas del jesuita ${ }^{30}$. Así, a pesar de que no ha sido hallada su escritura de contratación, si que podemos detectar que su esquema resulta deudor de las composiciones retablísticas diseñadas por Alonso Matías. Otras fuentes documentales son las encargadas de darnos a conocer los diversos artífices, algunos de ellos de origen malagueño, que intervinieron en el desarrollo de la obra. A este respecto, debemos tener en cuenta que esta circunstancia no es fruto de una mera casualidad, sino que don Luis Fernández de Córdoba ocupa en estos momentos la sede episcopal malagueña por lo que se relacionará con cierta frecuencia con los círculos de artistas de esa ciudad. De este modo, la talla es encomendada a los maestros Felipe Vázquez de Ureta y Juan Bautista de Botada, mientras que las labores de policromía (el dorado, estofado, las pinturas y encarnaciones), serán realizadas por los artistas cordobeses Andrés Fernández y Agustín de Borja ${ }^{31}$, sustituyendo éste último al fallecido Juan Cornejo al que originariamente le había sido asignada esta tarea. Otra referencia se encuentra en un documento que data del año 1620, en el que se manifiesta el compromiso por parte de Juan Bautista de Botada para la realización del segundo cuerpo y del remate del retablo ${ }^{32}$.

29 AROCA LARA, Ángel, "La escultura cordobesa del Seiscientos", en VALVERDE CANDIL, Mercedes (coord.), Antonio del Castillo y su época, catálogo de la exposición (Córdoba, 1986), Córdoba, Diputación Provincial de Córdoba, 1986, p. 178.

30 RAYA RAYA, María de los Ángeles, El retablo barroco cordobés, Córdoba, Publicaciones del Monte de Piedad y Caja de Ahorros de Córdoba, 1987, p. 259.

31 AHPCO, SPNCO, legajo 6, f. 48.

32 RAYA RAYA, María de los Ángeles, Catálogo de las pinturas de la Catedral de Córdoba, Córdoba, Publicaciones del Monte de Piedad y Caja de Ahorros de Córdoba, 1987, p. 41. 
Con relación al retablo podemos hacer algunas observaciones. La primera de ellas no es otra que la inexistencia de un programa iconográfico concreto, cuyo desarrollo nos permitiría alcanzar un conocimiento más profundo de la mentalidad de la personalidad que propone el encargo. A esta apreciación añadimos otra, más elemental si cabe, y es que consideramos que las imágenes, fundamentalmente las obras escultóricas, que actualmente se disponen en el retablo, no pertenecen a ese marco arquitectónico, sino que probablemente han sido añadidas a posteriori, de forma arbitraria, sin que exista testimonio del momento en el que se produjeron esos cambios. En este caso, dicho traslado de imágenes es el motivo que nos ha impedido conocer los asuntos iconográficos que habían sido seleccionados por el donante de la obra, don Luis Fernández de Córdoba. Por su parte, estas modificaciones también se insinúan al observar que su estructura parece haber sido rehecha ya que, por ejemplo, se diría que en la zona central se ubicaban unas columnas que actualmente han desaparecido. De todos modos, nuestro planteamiento acerca de las alteraciones que pudieron producirse en este retablo no sólo se sustenta en meras apreciaciones visuales, sino también en el conocimiento de que, en mayo del año 1622, el pintor Agustín de Castillo se compromete con el obispo de Málaga a realizar una serie de lienzos destinados al retablo mayor del templo parroquial de Guadalcázar. Pese a contar con esta noticia, no se conocen más datos sobre estas obras y actualmente se ignora su localización.

La villa de Guadalcázar siguió siendo beneficiada por las empresas de don Luis Fernández de Córdoba. Desde su visita por mandato real al monasterio de las Huelgas en Burgos y su conocimiento del espíritu de la Orden del Cister, el obispo albergó la idea de fundar un convento de la misma orden en la localidad cordobesa, y así se dispuso a hacerlo en cuanto sus ocupaciones de la diócesis malagueña se lo permitieron. El día 23 de noviembre de 1620 otorgó un poder a Antonio Baena para iniciar los trámites de fundación y dotación del que será el convento de la Inmaculada Concepción de la Orden de San Bernardo, actualmente extinto.

Ya con destino a la capital de Córdoba, en concreto para la capilla mayor del convento de San Francisco (lugar de enterramiento de parte de su ascendencia), encargará un retablo presupuestado en 800 ducados. La obra patrocinada por don Luis Fernández de Córdoba no se conserva ${ }^{33}$, pero el padre Andrés Llordén documenta cierta información relativa a su autoría. Así, podemos saber que su realización fue designada tanto a Pedro Martín de Polaino, escultor de Guadalcázar, como a Agustín de Borja y Alonso Fernández ${ }^{34}$, que emprenderían la labor del dorado.

Finalmente, queda concluir que, tal y como hemos podido apreciar a lo largo del desarrollo de nuestro estudio introductorio, Luis Fernández de Córdoba es un personalidad de prestigio en el contexto social, político y religioso de su momento. Dicha relevancia es la que permite que su legado quede perpetuado en el tiempo por medio de las empresas que se erigen bajo su patrocinio.

33 Dado que fue sustituida en la primera mitad del siglo XVIII por otro retablo, en este caso, una gran máquina de cuerpo único realizada por Teodosio Sánchez de Rueda.

34 LLORDÉN SIMÓN, Andrés, Escultores y entalladores malagueños. Ensayo histórico documental (siglos $X V$-XIX), Ávila, Ediciones Real Monasterio del Escorial, 1960, p. 202. 